\title{
Microstructure of Al/Ti diffusion couple by resistance spot welding and annealing
}

\author{
Yangyang Zhao', a, Ranfeng Qiu, b and Jiuyong $\mathrm{Li}^{1, \mathrm{c}}$ \\ ${ }^{1}$ School of Materials Science and Engineering, Henan University of Science and Technology, \\ Luoyang, 471003, China \\ a1053223247@qq.com, bqiurf1221@163.com, c24385965434@qq.com
}

\begin{abstract}
Keywords: intermetallic compounds, $\mathrm{TiAl}_{3}$, aluminum alloy, titanium
Abstract. Al-Ti diffusion couples prepared by resistance spot welding are annealed at $575^{\circ} \mathrm{C}$ for different time. The microstructure of the interface area was investigated. The result shows that there is no obvious intermetallic compound in the interface after welding. According to the SEM (scanning electron microscope) images, a continuous reaction layer is generated between $\mathrm{Ti}$ and $\mathrm{Al}$ matrix, and the thickness of the reaction layer increases with the annealing time goes by. A SEM equipped with energy dispersive X-ray spectroscopy (EDX) is used to identify the compounds of the reaction layer. The phase of the reaction layer is $\mathrm{TiAl}_{3}$, which is a kind of $\mathrm{Al} / \mathrm{Ti}$ intermetallic compound (IMC).
\end{abstract}

\section{Introduction}

In recent years, the $\mathrm{Al}-\mathrm{Ti}$ composites have attracted many research studies because of their exceptional properties such as high values of strength-to-weight and stiffness-to-weight, excellent low temperature toughness, corrosion resistance and low cost [1]. However, it is difficult to achieve reliable Al-Ti composite components because of the enormous differences between thermal and physical properties of $\mathrm{Ti}$ and $\mathrm{Al}$. As one of the most essential welding methods, resistance spot welding (RSW) is widely used to connect heterogeneous materials, especially thin plates. RSW is undoubtedly the ideal method to achieve Al-Ti composite components. However, the formation of $\mathrm{Al} / \mathrm{Ti}$ intermetallic compounds (IMCs) at the welding interface will degrade the mechanical property and service life of Al-Ti composite components [2]. So, the primary task is restraining the formation of Al/Ti IMCs when welding titanium and aluminum should be the primary task, and it is essential for us to study the formation and growth mechanism of Al/Ti IMCs.

The first work is manufacturing Al-Ti diffusion couples, and there are many methods in current reports. $\mathrm{L} . \mathrm{Xu}$ [3] investigated solid-state reactive diffusion between $\mathrm{Ti}$ and $\mathrm{Al}$ by employing multi-laminated $\mathrm{Ti} / \mathrm{Al}$ diffusion couples, found that both $\mathrm{Ti}$ and $\mathrm{Al}$ diffused into each into each other. To eliminate the effects of unavoidable contamination, L.M.Peng [4] fabricated $\mathrm{Ti}_{-} \mathrm{Al}_{3} \mathrm{Ti}$ laminated in vacuum, and indicated that only the intermetallic $\mathrm{Al}_{3} \mathrm{Ti}$ is formed and the diffusion processes occurring in liquid Al. Shu-ying JIANG and Shi-chun LI [5] fabricated Al-Ti diffusion couples by embedded technology, studied the growth mechanism of Al/Ti IMCs and suggested that the growth interface moves toward the aluminum side. Foadian $\mathrm{F} \mathrm{[6]} \mathrm{fabricated} \mathrm{Ti}-\mathrm{Al}_{3} \mathrm{Ti}$ laminated by explosion welding, and two mechanisms for $\mathrm{TiAl}_{3}$ growth exist in their study.

According above studies, the growth mechanisms of different diffusion systems in different methods are not completely same. So far, no scholars have used the Al/Ti diffusion couples prepared by resistance spot welding and studied its growth mechanism. In this paper, a simple Al-Ti diffusion couple was prepared by resistance spot welding, and annealing experiments were employed to study the growth mechanism of Al/Ti IMCs at the welding interface.

\section{Experimental}

Materials throughout the present study include aluminum alloy A6061 and commercial pure titanium sheets, and the thickness of A6061 and $\mathrm{Ti}$ are $2 \mathrm{~mm}$ and $1 \mathrm{~mm}$ respectively, and their chemical compositions are shown in Table 1. The experiment consists of resistance spot welding and annealing. 
Before welding, specimens were cleaned by acetone and ground with abrasive paper to remove the surface oxide film and external oil pollution. The welding experiments were performed using the DM-200 moderate frequency, direct current, resistance spot welding machine. During welding, the welding current, welding time and electrode force are $10 \mathrm{kA}, 200 \mathrm{~ms}$ and $1.7 \mathrm{kN}$ respectively.

Table 1 Chemical composition of materials (Mass \%)

\begin{tabular}{cccccccccccc}
\hline Material & $\mathrm{Ti}$ & $\mathrm{O}$ & $\mathrm{Fe}$ & $\mathrm{N}$ & $\mathrm{C}$ & $\mathrm{Mn}$ & $\mathrm{Cr}$ & $\mathrm{Cu}$ & $\mathrm{Si}$ & $\mathrm{Mg}$ & $\mathrm{Al}$ \\
\hline $\mathrm{Ti}$ & $\mathrm{Bal}$. & 0.14 & 0.07 & 0.02 & 0.01 & - & - & - & - & - & - \\
$\mathrm{A} 6061$ & 0.15 & - & - & - & - & 0.15 & 0.04 & 0.3 & 0.6 & 1.0 & Bal. \\
\hline
\end{tabular}

The welded specimens were cut along the maximum diameter of the weld spot. Annealing experiments were carried out at $575^{\circ} \mathrm{C}$ for different time $(2,4$ and $16 \mathrm{~h})$, then annealing samples were cooled in air. A scanning electron microscope (SEM, JEOL JSM-6300) equipped with energy dispersive X-ray spectroscopy (EDX) is used to identify the compounds of the reaction layer.

\section{Results and discussion}

SEM observations of the samples obtained at different experimental parameters are shown in Fig.1. Figure 1(a) shows the SEM images of Al/Ti interface region without the annealing experiment, the interface is well bonded and no other matters can be seen except $\mathrm{Al}$ and Ti matrices. Figure 1(b), 1(c) and 1(d) are SEM images of the interfacial area obtained by annealing the Al/Ti diffusion couple at $575^{\circ} \mathrm{C}$ for 2, 4 and $16 \mathrm{~h}$ respectively. Comparing with Figure 1(a), after annealing, the interface layer is composed of three parts, the Ti matrix of the gray region, the Al matrix of the black region and the interface reaction layer of dark grey region, no other substances generated in the current experimental conditions. The thickness of the reaction layer increases with the annealing time goes by.

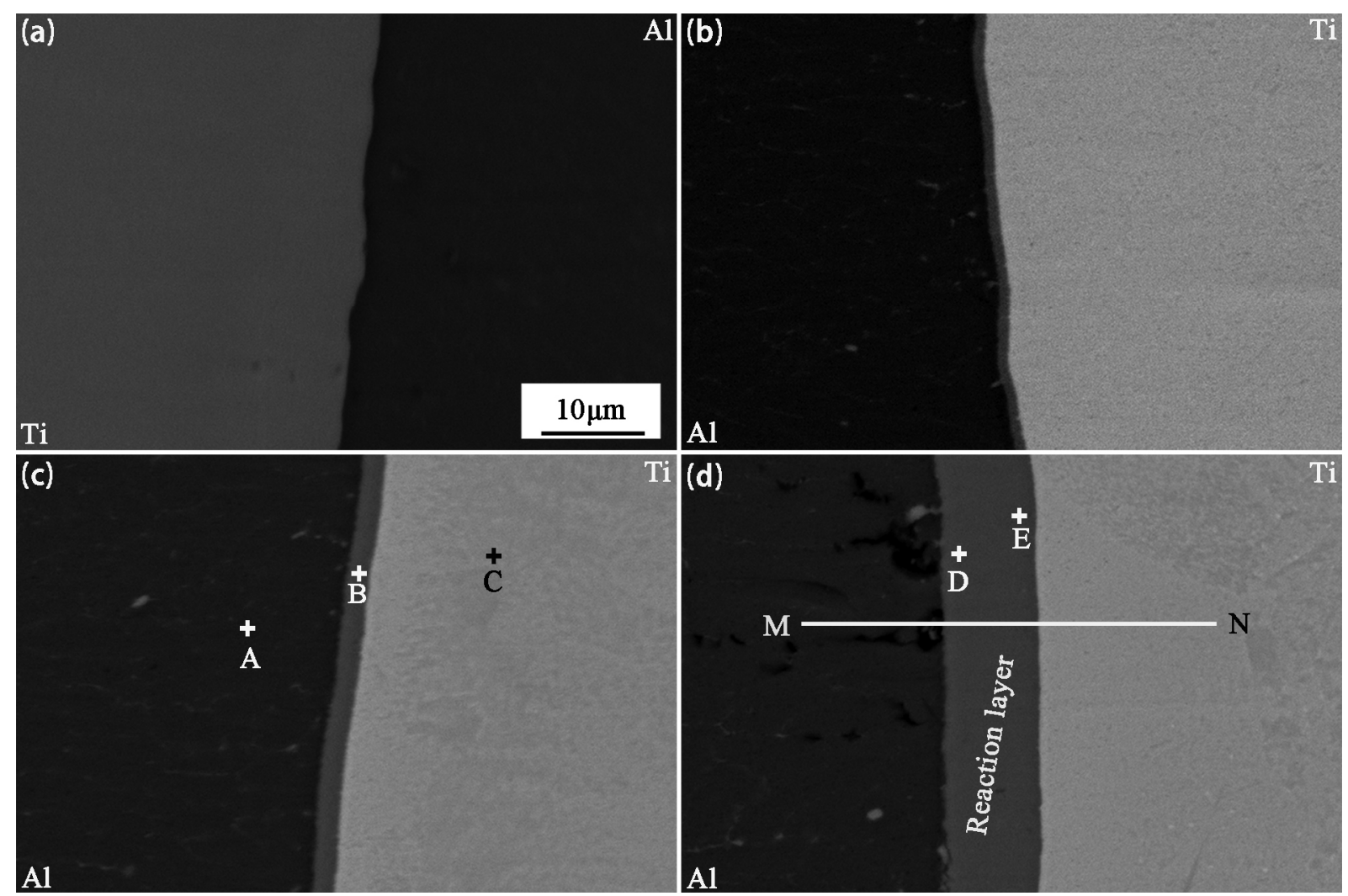

Fig. 1 Micrographs of the interface region of samples annealed at $575^{\circ} \mathrm{C}$ for $0 \mathrm{~h} \mathrm{(a),} 2 \mathrm{~h} \mathrm{(b),} 4 \mathrm{~h}(\mathrm{c})$, and 16h(d) 
In order to further understand the microstructure of the Al/Ti interface reaction layer, the sample annealed at $575^{\circ} \mathrm{C}$ for 4 and $9 \mathrm{~h}$ was investigated by EDX.

Table 2 The result of EDX point analysis of Ti/Al interface in Fig. 1 (c and d)

\begin{tabular}{ccccc}
\hline \multirow{2}{*}{ Position } & \multicolumn{3}{c}{ Composition (at \%) } & \multirow{2}{*}{ Phase } \\
\cline { 2 - 4 } & $\mathrm{Al}$ & $\mathrm{Si}$ & $\mathrm{Ti}$ & \\
\hline A & 99.44 & 0.25 & 0.31 & $\mathrm{Al}$ \\
B & 66.82 & 8.82 & 24.36 & $\mathrm{TiAl}_{3}$ \\
C & 0.27 & 0 & 99.73 & $\mathrm{Ti}$ \\
D & 68.90 & 6.26 & 24.84 & $\mathrm{TiAl}_{3}$ \\
E & 67.07 & 9.05 & 23.88 & $\mathrm{TiAl}_{3}$ \\
\hline
\end{tabular}

The positions of points are shown in Figure 1(c) and 1(d). And the results of the points analysis are shown in Table 2. The results demonstrate that the contents of $\mathrm{Al}$ atoms in points $\mathrm{A}, \mathrm{B}, \mathrm{C}, \mathrm{D}$ and $\mathrm{E}$, are $99.44 \%, 66.82 \%, 0.27 \%, 68.90 \%$, and $67.07 \%$ respectively. At first, assuming that the phase of the reaction layer is TiAl3.Zhu Guo-Liang [7] suggested that Si prefers to occupy the $\mathrm{Al}$ site in $\mathrm{TiAl}_{3}$, so $\mathrm{Si}$ should be viewed as $\mathrm{Al}$ when counting the contents. Finally, the contents of $\mathrm{Al}$ atoms in points $\mathrm{B}$, $\mathrm{D}$ and $\mathrm{E}$ are thought to be $75.64 \%, 75.16 \%, 76.12 \%$, which indicates that the phase is $\mathrm{TiAl}_{3}$ according to the Al-Ti binary phase diagram.

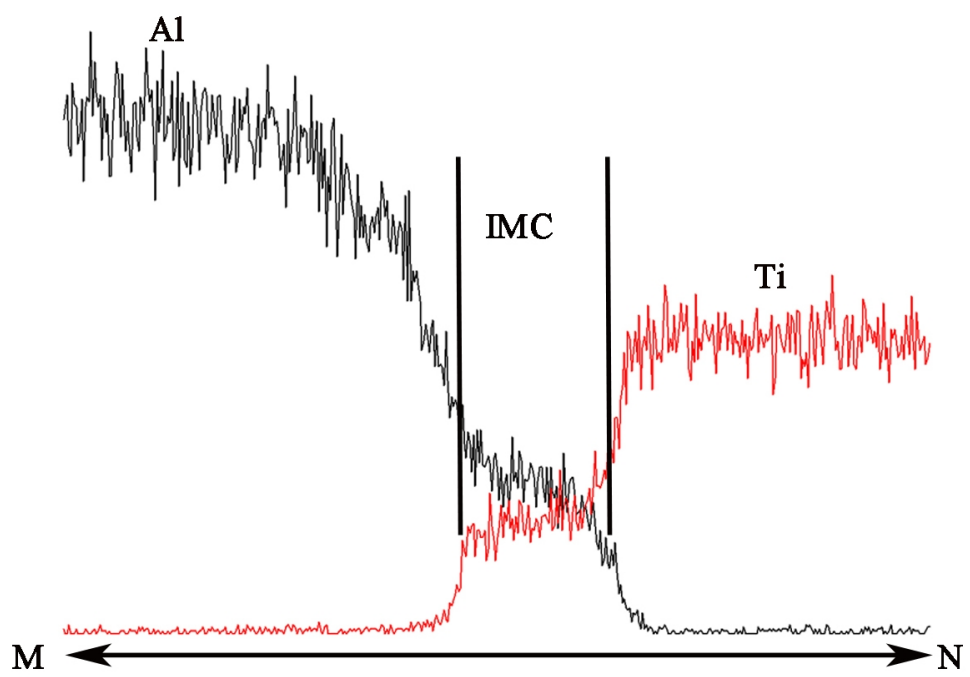

Fig.2 The result of EDX line analysis of M-N in Fig. 1(d)

As shown in Figure 1(d), the line analysis starts at the point $\mathrm{M}$ on the $\mathrm{Al}$ matrix and passes through the interfacial reaction layer, ending at point $\mathrm{N}$ on the $\mathrm{Ti}$ substrate, the curves of line scanning spectrum is shown in Fig.2, the compositions of $\mathrm{Al}$ and $\mathrm{Ti}$ change sharply in the interface between the reaction layer and the matrix of $\mathrm{Ti}$ or $\mathrm{Al}$, which indicates the formation of IMC. The stage of the curves of reaction layer is flat, contacting the above, only $\mathrm{TiAl}_{3} \mathrm{IMC}$ was generated among the experimental conditions in this paper.

\section{Conclusions}

The microstructure of Al-Ti diffusion couples prepared by resistance spot welding has been studied, and the main conclusions are summarized as follows:

1. The structure of the SEM image of the Al/Ti bonded interface region is composed of three parts, the Ti matrix of the gray region, the $\mathrm{Al}$ matrix of the black region and the interface reaction layer of dark grey region, and they are similar at different experimental conditions.

2. The thickness of the reaction layer increases with the annealing time goes by. 
3. The phase of the reaction layer is $\mathrm{TiAl}_{3}$, which is a kind of $\mathrm{Al} / \mathrm{Ti}$ intermetallic compound (IMC).

\section{Acknowledgement}

This work was supported by the Natural Science Foundation of China (U1204520), Henan Province Support Plan of Universities and Colleges Innovation Talents (16HASTIT050), Henan Province International Science and Technology Cooperation Projects (162102410023).

\section{References}

[1] R.L. Fleischer: J. Mater. Sci., 1987, vol. 22, pp. 2281-88.

[2] Li Y, Zhang Y, Luo Z. Science \& Technology of Welding \& Joining, 2015, 20(5):1362171815Y.000.

[3] Xu L, Cui Y Y, Hao Y L, et al. Materials Science \& Engineering A, 2006, s 435-436(4):638-647.

[4] Peng L M, Wang J H, Li H, et al. Scripta Materialia, 2005, 52(3):243-248.

[5] Jiang S, Liu S, Zhuang L. Transactions of Nonferrous Metals Society of China, 2013(23) $3545-3552$.

[6] Foadian F, Soltanieh M, Adeli M, et al. Metallurgical \& Materials Transactions B, 2016, 47(5):1-7.

[7] Zhu G L. Acta Physica Sinica, 2009, 58(13):S210-S215. 